\title{
Development of Fire Monitoring and Extinguishing Robot Using IoT
}

\author{
P.Deva ${ }^{1}$, Dr.Ramkumar prabhu ${ }^{2}$ \\ ${ }^{1}$ UG Scholars, Department of ECE, Apollo Engineering College, Chennai. \\ ${ }^{2}$ Professor, Department of ECE, Apollo Engineering College, Chennai..
}

\begin{tabular}{lcc}
\hline \multicolumn{3}{l}{ Article Information } \\
\hline Received & 20 April 2020 \\
Revised & $:$ & 28 May 2020 \\
Accepted & $:$ & 03 June 2020 \\
Published & $:$ & 13 June 2020
\end{tabular}

Corresponding Author:

P.Deva

Email: devashakthi29@gmail.com

\begin{abstract}
The purpose of the research project is develope to an autonomous moving and controlling the vehicle that capable of file extinguishing automatically and access by anywhere in the world using IoT. This robot is detecting the fire and taking appropriate distinguisher operation just to protect the human's life. The robot consist of Flame sensor and Gas sensor that detects the fire, smoke as well as gas leakage. Whenever it detects the fire it will be extinguishing fire by sprinkling the water into the fire. The obstacles can be identified by ultrasonic sensors The video and audio can be accessed anywhere by using the webcam installed on it. We can control the robot using wifi as well as IoT. The data collected has been sent through the cloud server and can access the data across the world using IoT.
\end{abstract}

Keywords: Arduino UNO, Flame Sensor, Gas Sensor, NodeMcu, Temperature Sensor, Ultrasonic sensor, Water Sprinkler.

Copyright (C) 2020: P.Deva. This is an open access distribution, and reproduction in any medium, provided Access article distributed under the Creative Commons Attribution License the original work is properly cited License, which permits unrestricted use.

Citation: P.Deva, Dr.Ramkumar prabhu, "Development of Fire Monitoring and Extinguishing Robot Using IoT, "Journal of Science, Computing and Engineering Research, 1(2), 47-51, May-June 2020.

\section{INTRODUCTION}

Now a days the automation using IoT is developing in all fields. Fire safety is most important thing for an industry as well as home and office. A big threat for human life nowadays one of the reason is fire. The firefighting robot can extinguishing the fire quickly when it detects.so that the fire doesn't spread and there is no waiting for the firemen and there is no need of fire extinguishing by humans. This research project is advanced firefighting robot by using IoT and wifi technologies.

Firefighting robots are very much essential for different places where to protect the expensive things as well as human life in different places. So that in the real time world we are designing an autonomous firefighting robots for extinguishing the fire. Right now the firefighters are extinguishing the fire with help of water, but most of the time the fire is spreading before taking an action so lots of losses are happening. To avoid such kind of situation these robot can help to prevent the human being before they gets injury

\section{RELATED WORKS}

Ratnesh Malik et al. gives an idea for autonomous robot for extinguishing the fire. This robot consist of several sensors. From those sensors its getting environmental information under normal condition. In case existing of fire it can be identify through sensors and it can sprinkle water to shut the fire.[1]

Kristi Kokasih et al. has autonomous tank robot designed and implemented resins and iron. It consist of several sensors along with servo motor and dual tone multifrequency transmission system [2]. H.P. Singh et al. has done industrial firefighting robot. It can identify the fire flame with help of flame sensors and starting the process of extinguishing with water which can be stored in container. This robot is having 3DOF [3]. Swati Deshmukh et al explain about remotely operating robot which is based on wireless communication. The main advantage of this robot is to sprinkle water for more distance after getting signal from sensors[4]. Lakshay Arora that comprises mobile phone based firefighting robot. Principle of this robot will be call activation (DTMF) based robot. It receives call from concern person and it will take appropriate action [5].

\section{HARDWARE OVERVIEW}

\section{A. Arduino Uno R3}

Arduino UNO is type of microcontroller which is having readymade IDE software. Output of the sensors which may be available either analog of digital is given to microcontroller for further action. 


\section{B. NodeMcu}

NodeMCU(ESP8266) is firmware for designing. It can be used for combining Arduino and nodes.

\section{Five Channel Flame Sensor}

A type of flame sensor using in this autonomous robot is 5channel flame sensor. The advantage of this sensor will covers the area in large approximately $120^{\circ}$. Its more precise and reliable, hence output of this sensor boosted because operating voltage is vary from $2.5-5 \mathrm{v}$.

\section{L298N Motor Driver}

L293D is bidirectional DC motor drive which can help to drive the autonomous robot in required direction with particular speed.

\section{E. Gear Motor}

Gear motors having high torque with less speed. The rating of this motor is $12 \mathrm{v}$ operating voltage with maximum speed of $200 \mathrm{rpm}$.

\section{F. Gas Sensor}

Gas sensors (MQ9) are identifying different types of gases in atmosphere. This type of sensors are responding very quickly so response will be higher compare to other types.

\section{G. Temperature Sensor}

DHT11 or DHT22 are digital type of temperature sensors which is available in current advancement of technology. Operating range will be vary from -50 to $100^{\circ} \mathrm{C}$.

\section{H. Ultrasonic Sensor}

HC-SR04 Ultrasonic (US) sensor is used to identify the obstacle when robot is moving forward. it given signal to Arduino uno to change the speed and direction.

\section{Distance $=$ Speed $\times$ Time}

\section{BLOCK DIAGRAM AND FUNCTIONAL DESCRIPTION}

As discussed earlier, the Block Diagram consists of several components which are used for the control and interfacing of the android controlled IoT and autonomous firefighting robot. In this research project the robot can be controlled by wifi and IoT. The Main components arduino module and the NodeMcu module are used as the microcontroller units. Here the temperature and gas sensor is used to find out the temperature and air quality of the area. Flame sensor is used to -monitor the fire occurrence. Camera is used to view the exact situation of the area. All these components are controlled by Arduino and NodeMcu boards. Android application is used to control the motor and display the sensor values and gives the alert messages. The block diagram of the research research project is given below.

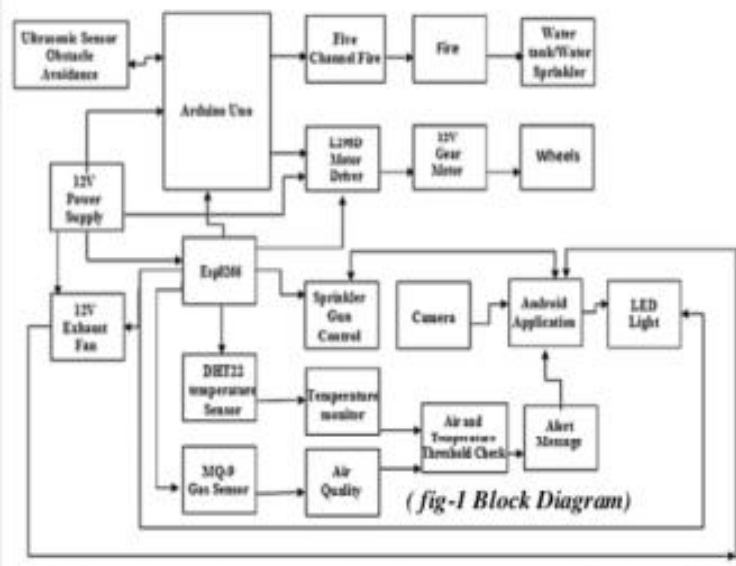

Figure 1 Block Diagram

- The firefighting robot that enhanced with the IoT application.

- The NodeMcu Esp8266 with the wifi module that connect with the internet to use the IoT.

- If any fire is detected by the robot it automatically directed to the area under fire to extinguish the fire.

- The robot also can be directed by the wifi and IoT control to extinguishing fire.

- The robot has the water tank capacity and the water sprinkler.

- The Ultrasonic sensor HC-SR04 used to check the obstacles in the robot way and help to directed the robot without hitting on the obstacles.

- Here the temperature sensor DHT22 sense the temperature up to $-40^{\circ}$ to $80^{\circ} \mathrm{C}$.

- If the temperature is greater than the $38^{\circ} \mathrm{C}$ alert message sent to the android application and to the fire station via the SMS.

- The gas sensor MQ-9 can detect LPG, CH4, CO, Alcohol, Smoke or Propane. The air quality can be monitor by the android application and this helps to fireman/people find out the air quality of the fire surrounded area.

- If the smoke is high the exhaust fan is on to romove the smoke and get clear view in camera.

- Here the ip webcam app gives a view of the exact situation on that area via tha android application by the ip surveillance.

- LED light gives the better view in dark area and it can be switch using wifi app and IoT app.

- The robot can controlled by WiFi as well as through the internet via the android application. 
- Here motor driver L298N is used to control the gear motor.

This fire monitoring and extinguishing robot can be implemented on the industrial areas, home as well as forest areas. The robot mainly designed for the industrial area which should have high possible of fire occurring.

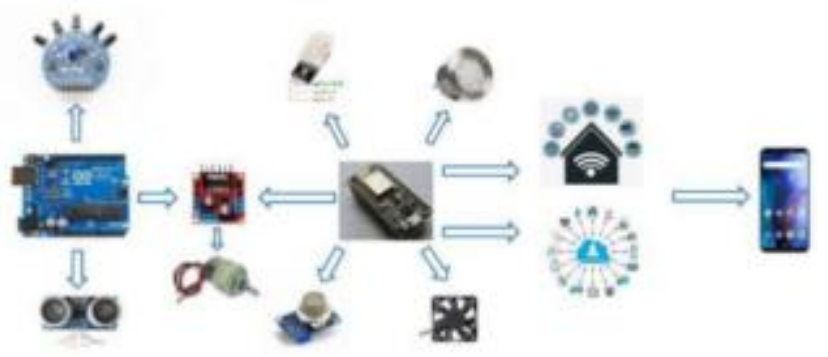

Figure 2 Functional Diagram

V DESIGN AND IMPLEMENTATION

\section{A. Arduino IDE}

This is programming software based on java contains its own library. The fundamentals are based on $\mathrm{C}$ programming then it will be very much easier to burn the program to chip.

\section{B. Blynk}

In case if the robots are operating with help of mobile phones either android of IOS this BLYNK is used to transfer data from mobile to Arduino.

\section{MIT App Inventor-2}

This is one given by google for integrating web applications. This application is suitable for both android and IOS soft wares. The robot consist of two modes of operation and it can be controlled by the IoT and Wi-Fi applications from the android phone.

\section{Automatic Mode}

In the Autonomous mode robot automatically moving and avoid obstacles using the ultrasonic sensor built in it. The robot can able to detect the fire using the five channel flame sensor and tracking the fire and extinguish it. Generally the robot in the controller mode. The mode can be change using IoT and WiFi through the android applications. The audio, video and Temperature and Air quality also monitor using the android applications. From the above flow graph when the robot turn on it will on the motor, ultrasonic sensor, Temperature sensor, Gas sensor and the flame sensor. Flame sensor searching for the fire if any fire occurs it will trig the sprinkler gun and track the fire and then extinguishing it. If temperature value greater than the $38^{\prime} \mathrm{C}$ then the alert message "Temperature is too high" will going to the users mobile and fire station to send the fire fighters to the location. If the $\mathrm{CO}$ values greater than $70 \mathrm{ppm}$ it will intimate air quality is poor to the user mobile phone. The Temperature and Air quality values can be viewed by the android app using IoT. The camera gives the audio and video can be view in the android applications.

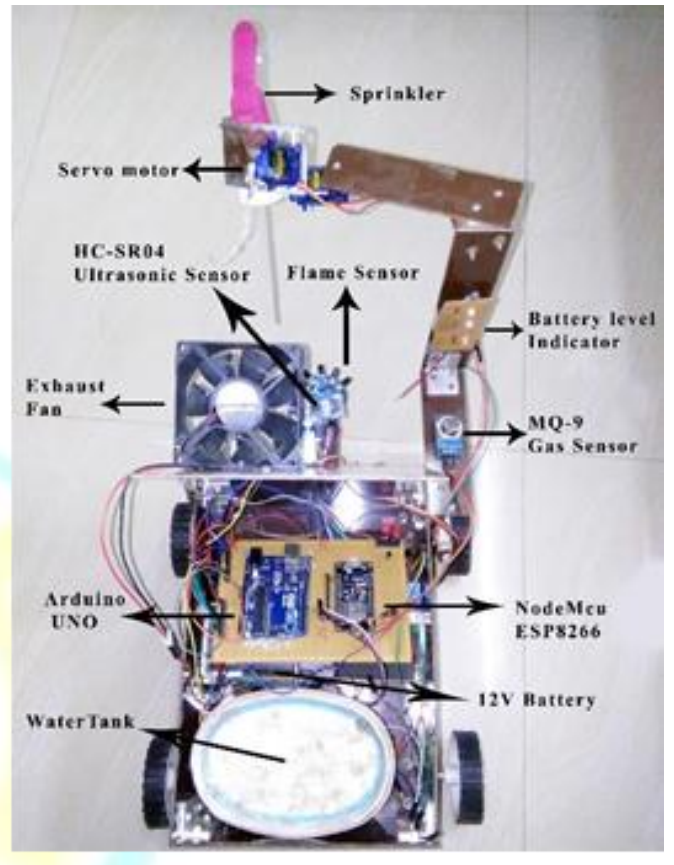

\section{E. Controller Mode}

Figure 3 Parts of Robot

In the controller mode the robot moments, Led light, Exhaust fan and the Sprinkler gun can be controlled manually using IoT and Wi-Fi through the android application. Generally the controller mode is in action. The mode can be change by mode switch using the application. Here we can control the all things installed in the robot.

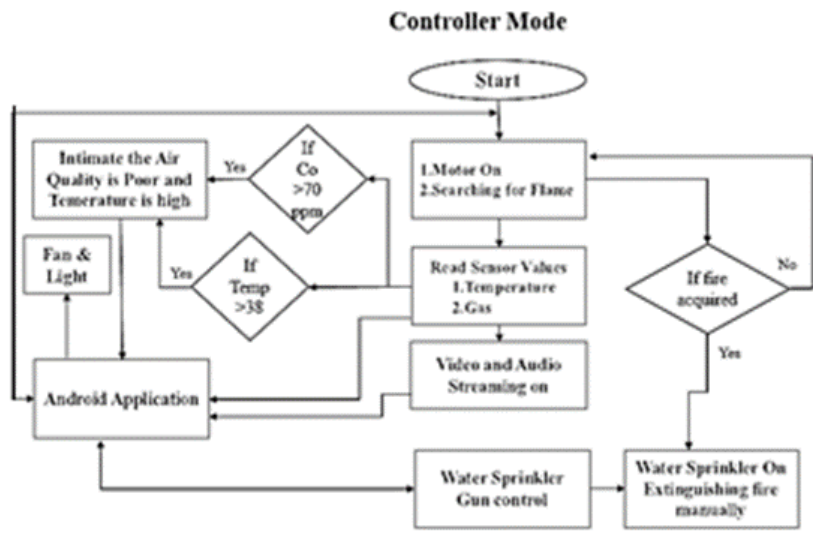

Figure 4 Controller Mode 
From the above flow graph when the robot turn on it will on the motor, ultrasonic sensor, Temperature sensor, Gas sensor and the flame sensor.

- Flame sensor searching for the fire if any fire occurs it will trig the sprinkler gun and then extinguishing fire by controlling the sprinkler gun using the android app.

- If temperature value greater than the $38^{\prime} \mathrm{C}$ then the alert message "Temperature is too high" will going to the users mobile and fire station to send the fire fighters to the location.

- If the $\mathrm{CO}$ values grater than 70ppm it will intimate air quality is poor to the user mobile phone Temperature and Air quality values can be viewed by the android app using IoT

- The camera gives the audio and video can be view in the android applications

- The sprinkler gun can be rotate upto 0 to 180 degrees from the middle. It will spray the water into the fire top to bottom of the area.

- There is a LED light used to drive the robot in dark area and night times and it can be ON/OFF by the android app.

- Exhaust fan used to send out the smoke in the fire occurred area/room and provide the better view for the camera. It can be ON/OFF by android app.

The figure shows the controllers apps for the fire monitoring and extinguishing robot. By these apps we can interface with the robot and sending commands. C.Controlling robot

\section{EXPERIMENTAL RESULT}

\section{A. Hardware Preview}

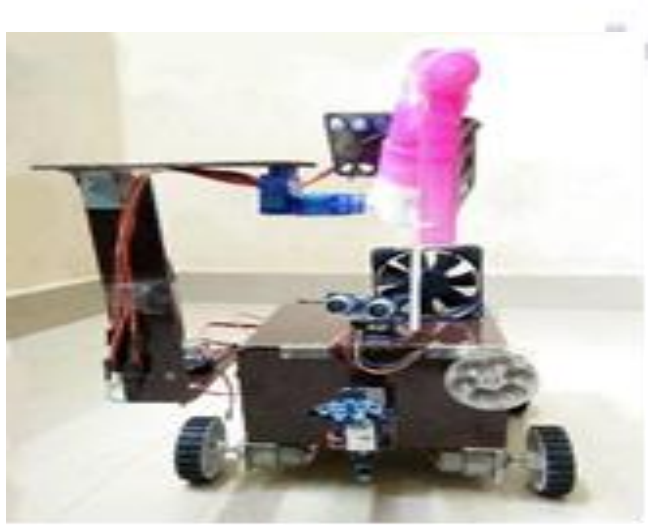

Figure 5 Hardware Preview

\section{B. IoT \& WiFi App Control}

By using these apps we can control the motor movement, light on/off, Exhaust fan on/off, sprinkler positions and also modes can be changed. The fig-7(A\&B)

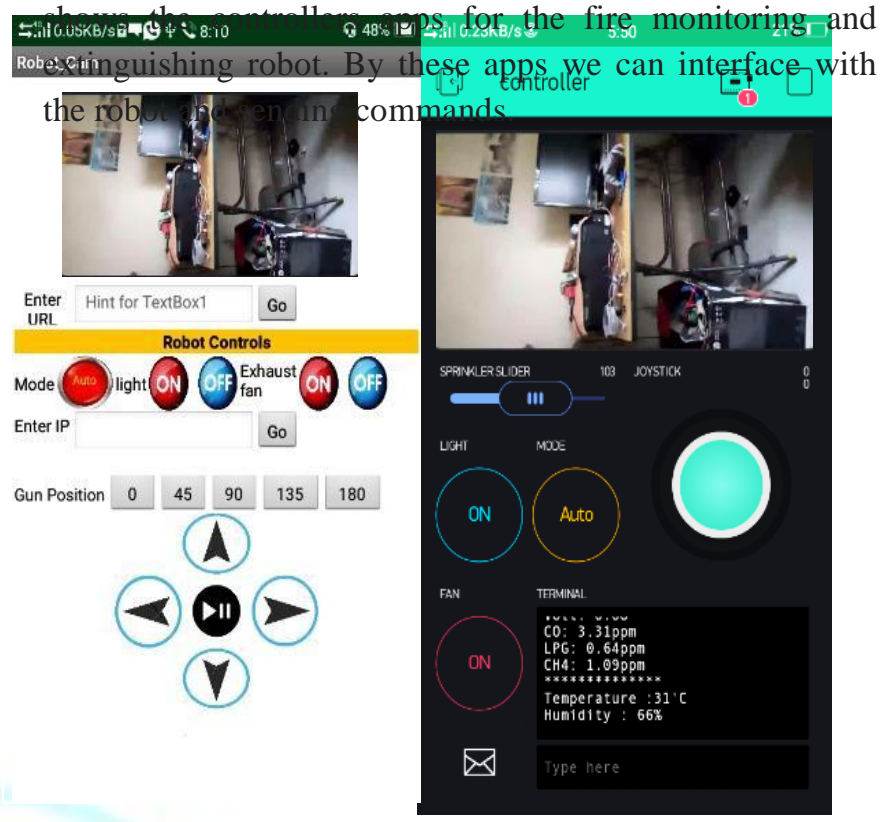

Figure 6 WiFi App Control

\section{Controlling robot}

The figure shows that the controls of the robot. we can control the motor movement, light on/off, Exhaust fan on/off, sprinkler positions and also modes can be changed.

\section{Temperature and Air Quality Monitoring}

The figure shows the Temperature and air quality monitoring. In normal conditions the Co,LPG and $\mathrm{CH} 4$ values are less and dose not harmful. In High temperature and Poor air quality conditions the temperature is high also
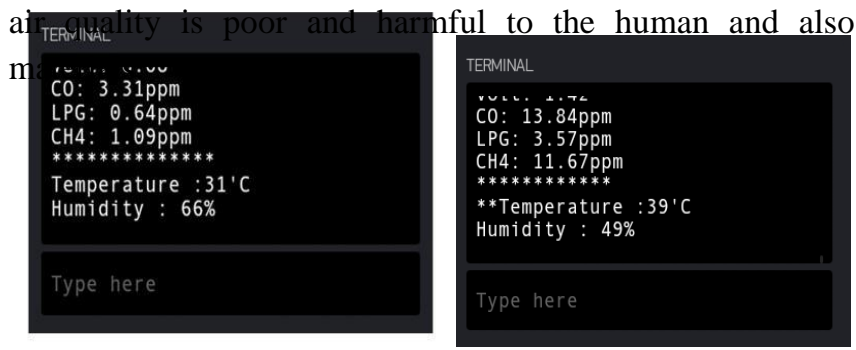

Figure 6 Temperature and Air Quality Monitoring

\section{E. Message Alert and Push Notification}


The above figure shows when the temperature and the air quality is poor the text message and the push notifications send to the user mobile phone. The alert message also send to the fire station and request to send the fire fighters to the correspondent location.
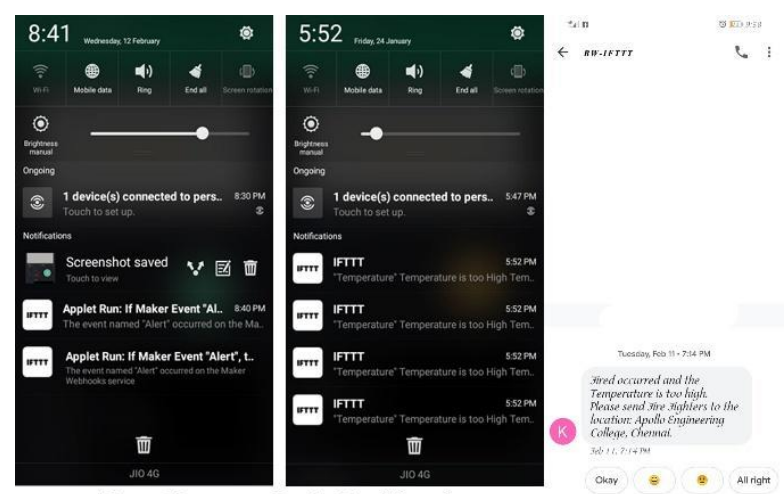

Alert Message Push Notification

Figure 7 Message Alert and Push Notification

\section{CONCLUSION}

This research project which is firefighting autonomous robot is designed for fighting against fire accident to save human life in appropriate time with high efficiency. The principle of fight is based on sprinkling the water which can be acting extinguishing medium against fire. This robot can be implemented with IoT based application through android or IOS phone.

\section{REFERENCES}

[1] Ratnesh Malik, "Fire Fighting Robot: An Approach", Indian Streams Research Journal Vol.2, Issue.II/March; 12pp.1-4

[2] Kristi Kosasih, E. Merry Sartika, M. Jimmy Hasugian, danMuliady, "The Intelligent Fire Fighting Tank Robot", Electrical Engineering Journal Vol. 1, No. 1, October 2010

[3] H. P. Singh, Akanshu Mahajan, N. Sukavanam, VeenaBudhraja, "Control Of An Autonomous Industrial Fire Fighting Mobile Robot", DU Journal of Undergraduate Research and Innovation.

[4] Swati A. Deshmukh, Karishma A. Matte and Rashmi A.Pandhare, "Wireless Fire Fighting Robot", International Journal For Research In Emerging Science and Technology.

[5] Lakshay Arora, Prof.AmolJoglekar, "Cell Phone Controlled Robot with Fire Detection Sensors", (IJCSIT) International Journal of Computer Science and Information Technologies, Vol. 6 (3), 2015, 2954-2958.

[6] Arpit Sharma, ReeteshVerma, Saurabh Gupta and Sukhdeep Kaur Bhatia, "Android Phone Controlled Robot Using Bluetooth", International Journal of Electronic and Electrical Engineering.ISSN 0974-2174, Volume 7, Number 5 (2014), pp.443-448

[7] Saravanan P, "Design and Development of Integrated SemiAutonomous Fire Fighting Mobile Robot", International Journal of
Engineering Science and Innovative Technology (IJESIT) Volume 4, Issue 2, March 2015

[8] Poonam Sonsale, RutikaGawas, Siddhi Pise, Anuj Kaldate, "Intelligent Fire Extinguisher System", IOSR Journal of Computer Engineering (IOSR-JCE) e-ISSN: 2278-0661, p-ISSN: 22788727Volume 16, Issue 1, Ver. VIII (Feb. 2014), PP59-61.

[9] Phyo Wai Aung, Wut Yi Win, "Remote Controlled Fire Fighting Robot", International Journal of Scientific Engineeringand Technology Research Volume.03,IssueNo.24,September-2015 